\title{
ADKAR Model in Change Management
}

\author{
HOVHANNES ANGTYAN \\ Terlemezyan 2, Yerevan, Armenia \\ E-Mail: angtyan08@gmail.com \\ Phone: +37498917575
}

\begin{abstract}
Any successful change begins by answering one of the basic questions about change: Why? It is human nature to want to understand the reasoning behind an action or a required change. Change is often hard, complicated and complex process. Leading successful change in other people and across whole organizations requires new things and new tools. The ADKAR model is a valuable framework for organizational leaders, change managers and project managers to effectively lead a wide variety of changes. The lens of ADKAR reveals both key concepts that influence successful change actionable insights for implementing these concepts.
\end{abstract}

Keywords: ADKAR Model, Change, Organizational Change, Awareness, Desire, Knowledge, Ability, Reinforcement.

\section{Introduction}

Change is often a complex and difficult process and it's inevitable. The most commonly cited reason for project failure is problems with the people side of change. Yet organizations often invest more in the technical side of change than in leading impacted people through times of change. The first step in managing any type of organizational change is understanding how to manage the change that a single individual is experiencing. Driving successful change in individuals and organizations requires new thinking, new models for change, and new tools. The ADKAR Model is proven to help organizations achieve the greatest benefits from their change initiatives.(1)

The ADKAR model of change is a practical answer to effective change management for individuals and organizations. The model is developed from a study of 900 organizations across 59 countries over a 14-year period, carried out by the US research organization, Prosci.(2) The model is simple to learn, makes sense, and focuses on the actions and outcomes required for change.

While many change management projects focus on the steps necessary for organizational change, ADKAR emphasizes that successful organizational change occurs only when each person is able to transition successfully. This model, developed by Jeff Hiatt, and first published in 2003, focuses on 5 actions and outcomes necessary for successful individual change, and therefore successful organizational change.

(A) Awareness of the need for change.

(D) Desire to support the participate in the change.

(K) Knowledge of how to change.

(A) Ability to implement the change.

(R) Reinforcement to sustain the change. 
Hiatt refers to each of these five actions as building blocks for successful individual change, and therefore successful organizational change. As the graphic indicates the process is sequential. In other words, each step must be completed before moving on to the next. Hiatt emphasises that it is not possible to achieve success in one area unless the previous action has been addressed.(3)

The ADKAR model consists of five sequential steps or actions:

1. Awareness of the need for change. Understanding why change is necessary is the first and main key aspect of successful change. This step explains the reasoning and thought that underlies a required change. Planned communication is essential. When this step is successfully completed the individual (employee) will fully understand why change is necessary. Here are a few factors, how people are aware of the need for change.

Factor 1 - A persons view of current state

Factor 2 - How a person perceives problem

Factor 3 - The credibility of the sender.

Factor 4 - Circulation of misinformation or rumors

Factor 5 - Contestability of the reason for change(4).

2. Desire is the second element of the ADKAR model and represents the motivation and ultimate choice to support and participate in a change. Unlike awareness-building, where we can make definition steps to generate the awareness of the need of change, creating the desire to change remains elusive and not under in our control. Naturally a desire to support and be part of the change can only happen after full awareness of the need for change is established. A common mistake made by many business leaders is to assume that by building the awareness of the need for change they have also created the desire.

Understanding the factors that influence the individual's desire to change is an important first step to achieving this element of the ADKAR model.

Factor 1 - What the change is and how I will impact them

Factor 2 - Their perceptions of the organizations

Factor 3 - An individual's personal situations

Factor 4 - What motivated them(5)

3. Knowledge is the third building block of the ADKAR model, and represents how to implement the change. This element providing knowledge about the change, that can be achieved through normal training and education methods. Other methods of transferring knowledge are forums and coaching. The mentoring is equally useful, so don't limit this process to formal training. Two types of knowledge need to be addressed: knowledge on how to change (what to do during the transition) and knowledge on how to perform once the change is implemented. Here are several factors, which will impact the successful achievement of knowledge element.

Factor 1 - The current knowledge base of an individual

Factor 2 - Capability of the person to learn

Factor 3 - Resources available to provide education and trainings

Factor 4 - The access of the required knowledge(6)

4. Ability is the fourth element of the ADKAR model and represents the demonstrated capability to implement the change and achieve the desired performance level. In this model Ability is understood to be the difference between theory and practice. Once knowledge on how to change is in place (theory) the practice, or actual performance of the individual, needs to be supported. This can take some time and can be achieved through practice, coaching and feedback. 
Awareness, desire and knowledge are all major elements, but fall short of realizing change if ability is absent. When the person achieves this element of the model the change is visible and measurable.

Several factors can impact a person's ability to implement change, including:

Factor 1 - Psychological blocks

Factor 2 - Physical abilities

Factor 3 - Intellectual capability

Factor 4 - The time available to develop the needed skills

Factor 5 - The availability of recourses to support the development of new abilities(7)

5. Reinforcement to sustain the change. This final stage of the model is an essential component in which efforts to sustain the change are emphasised. Ensuring that changes stay in place and that individuals do not revert to old ways can be achieved through positive feedback, rewards, recognition, measuring performance and taking corrective actions. This is often the part of change management that is most difficult as organizations are already moving towards the next change. For successful change, reinforcement is essential to ensure that changes are maintained and new outcomes can be measured. Some factors that influence reinforcement.

Factor 1 - The degree to which reinforcement meaningful

Factor 2 - Association of reinforcement with achievement

Factor 3 - The absence of negative results

Factor 4 -Accountability mechanisms to reinforce the change

Two dimensions: Change occurs on two dimensions: the organization and the employees. Change can only be successful if the change takes place simultaneously on both dimensions. If stagnation surfaces in one of the building blocks in the ADKAR model, then it is advisable to take action with respect to this element. This targeted approach focuses on the element with the highest chance of success. The ADKAR model does not just help to determine in advance what steps need to be taken to achieve the right goal, but it also identifies, with the benefit of hindsight, why changes have not been successful. This evaluation is valuable because it can help realize the change after all.(8)

\section{Why use the ADKAR model of change?}

The primary reason this model of change management is it's focus on individual change and ensuring each person makes the transition. This is more than a 'soft' approach, it has practical applications.

Most importantly, when you're focusing on the individual you're able to measure where they are in the change process and what is required to assist them. You are not simply relying on running a certain number of training programs, or communicating a particular message, and expecting everyone to follow.

- The model directs change management activities. It's focused on outcomes, not tasks to be performed. Many change models describe what needs to be done - this model describes the outcomes (Awareness, Desire, Knowledge, Ability, Reinforcement).

Communication strategies can be focused.

- The ADKAR model helps to measure the effectiveness of the change process. Progress can be measured down to the individual level, gaps diagnosed, and corrective action is directed.

- Managers have a tool they can use. Each part of the model gives manager's a specific role. For example, an individual struggling with change may need knowledge on how to change or may lack the ability to implement necessary skills or behaviors. The manager is able to discern between the two and can provide 
training (knowledge and information) or work closely with the individual, coaching them to give them the confidence (and ability) to perform effectively.

- This change management model can be used for both project and non-project change, and is effective as a model of individual change outside of the organizational setting as well.(9)

As already stated, there are 2 points that the successful change program will eventually have while using the change management process.

- process of change management, concentrating on the hard tangible side of change, meaning that by this, the processes of change management plan start

- process of the transition of people, which is the soft side, meanwhile the hardest part to be implemented. By this step the individuals change their attitude to what was planned or desired if the change was successful.

If these 2 parts are successfully accomplished, the project can be considered successful. After ensuring that the cultural change is happening and is going through a planned path, the business may close its project objectives and tasks. The above discussed model - ADKAR, can go well with the change management process based on the analyses done. Within its 5 phases, it might be mostly helpful when preparing people for change, creating that change or transition plan, and will be useful in understanding how well the change is happening or in trying to assess its performance. With the help of the model, it will be easier to highlight any gaps or any areas that might be improved later on.

\section{References}

https://www.accipio.com/eleadership/mod/wiki/view.php?pageid=65

https://www.accipio.com/eleadership/mod/wiki/view.php?pageid=65

https://www.change-management-coach.com/adkar.html

https://www.change-management-coach.com/adkar.html

https://www.change-management-coach.com/adkar.html

https://www.prosci.com/adkar/adkar-model

https://www.prosci.com/adkar/adkar-model

https://www.toolshero.com/change-management/adkar-model/

https://www.toolshero.com/change-management/adkar-model/

Jeffery M. Hiatt, ADKAR: The model for change in Business, Government, and Our Community,(2006) p. 9

Jeffery M. Hiatt, ADKAR: The model for change in Business, Government, and Our Community,(2006) p.18

Jeffery M. Hiatt, ADKAR: The model for change in Business, Government, and Our Community,(2006) p. 27

Jeffery M. Hiatt, ADKAR: The model for change in Business, Government, and OurCommunity,(2006) p.32

Jeffery M. Hiatt, ADKAR: The model for change in Business, Government, and Our Community (2006) 